\title{
Making a university in the desert
}

New Mexico, which has an estimable university already, is hardly the state in which one would expect to find the embryo of a centre of excellence. But that is what a handful of brave people plan.

THE Sante Fe Institute has everything going for it except big bucks, but even the budget is beginning to look quite healthy. That seems to be the general opinion at what is admittedly high season for the institute, physically on the edge of what remains a sleepy tourist city. Contrary to general expectation, the town is not the Sante Fe Railroad's railhead, which is some miles away, while its function as the state capital of New Mexico is similarly disguised by the grand buildings left over from the old colonial rule (by Spain).

The plusses are easily appreciated. As in much else of the South-West of the United States, the sky is usually cloudless unless (this is one of the rainy seasons) it is delivering a torrent of warm water. There is a quaintness about the region; Indian villagers seem to keep up their traditional rain-dances as much for their own benefit as for that of onlookers, but also prudently offer their skill at drilling artesian wells as a service to incomers to the region. And every skyline is a surprise.

But the institute's most important geographical asset is the Los Alamos National Laboratory, thirty miles away on the top of its still-unspoiled mesa. It is not so much that there are substantial crumbs of financial comfort to be found beneath such a rich man's table (federal regulations see to that), but that people at Los Alamos seem wholeheartedly to have welcomed the plan to found a free-standing intellectual enterprise on their doorstep, partly because the South-West is, after all, a long way from elsewhere.

If George Cowan, the director of the institute, has his way, there should be ample opportunities for intellectual trading between the two establishments. The institute has been founded by people who are predominantly theoreticians - people such as Murray Gellman (Caltech) and David Pines (Illinois at ChampagneUrbana) are members of the Scientific Board. So is Cowan trying to make a replica of the theoretical institute at Santa Barbara? Not a bit of it. The trouble with Santa Barbara, he says, is that it's almost part of a university. Cowan, almost immodestly for such a personally modest man, says that the goal at Sante Fe is to make a university. Nothing less.

The model is the Rockefeller University in New York, which also began life as a mere institute - and which might still be so called had it not been for the exuberant immodesty of the late and visionary
Detlev W. Bronk. Cowan's dream is of a faculty of about 100 people, with two or three times as many colleagues - postdoctoral people and students. But he and his colleagues, theoreticians though they may be, are prepared to take an empirical view of the timescale - ten years from now or "when I'm no longer here" provide what might be called, in other contexts, an open reading-frame.

The implication is that, while the institute as it is appears to have satisfied itself and its managers that it can keep on making progress, a little luck could make a big difference and a lot of luck could dramatically telescope the future. Students of academic entrepreneurship should perhaps visit before the beginnings of this enterprise have been buried by its success.

One thing that visitors will notice is that the institute has settled on an organizing principle that must command general attention: complex systems. Cynics may choose to score two cheap points at this stage. Complex systems, they may say, are defined by theoreticians as those that cannot now (or yet) be handled and, nevertheless, given that chaos and fractality have become fashionable, are all the rage.

Modest Cowan has a telling answer. Complex systems is not a synonym for "insoluble problems", but rather a pointer to a class of problems which are soluble with techniques that now exist. Their common ingredients are that one must begin with a kind of taxonomy, categorizing either the states of the system in interesting ways or the classes of soluble problems according to the techniques required. Then one must acknowledge that complex systems have a memory of a kind - their macroscopic future is determined not simply by their macroscopic present in what might be thought a Newtonian way, but by their microscopic present. Finally, and luckily, computation is coming to be the equal of all this complexity.

Last week's outcome of this optimism was the assembly of this year's summer school, which Cowan insists is misnamed. He intends that it should not be a school at which graduate students fill their notebooks with information to which their fellow-students will not have access, but rather an institution at which people will have to think for themselves; the last week of four (it seems a short time) is given over to a project or a problem.

Feigenbaum (of chaos) will be one of those giving four formal lectures and staying on to answer questions. So will be Stephen Wolfram, the ex-Caltech exPrinceton alumnus whose strong suit of cellular automata appears to satisfy all of Cowan's criteria for a complex system. Is it a disaster that these people will find themselves speaking in rented space in the parochial (= "Catholic") school across the road?

That, they should reflect, is what academic entrepreneurship is all about. Last year (1988), the Sante Fe institute spent about $\$ 800,000$. This year, it is planning to spend about $\$ 1.5$ million (but about $\$ 250,000$ remains to be found, although everybody is confident that it will be). Next year, the plan is to spend about $\$ 2.5$ million on intellectual activity, some of which is already promised or effectively guaranteed by the efforts of those who are now part-time members of the faculty.

Meanwhile, the institute has a problem with which it is confronted every day: there is no place to sit. The rented adobe building that half-accommodates the institute is, for practical purposes, simply a covered corridor with offices on either side. Claustrophobics may be happier in the permanently-rented accommodation in the parochial school across the road. That every office appears to have its own Sun workstation is probably as much a measure of where people come from as of the stripling institute's largesse.

Cowan's immediate goal is to find the funds with which to build a better building, somewhere permanent. That is where the luck will matter. He needs a benefactor who must be (by the US federal government's definition) different from the federal government.

Otherwise, there is a risk that the institute's affairs will be too much determined by the people who have chosen to support what it is already doing. Citibank, for example, appears to have seen the light by recognizing that economics is also a complex system, but can the institute succeed if nearly half its budget comes from such a source, and if its programme is skewed accordingly? The vertebrate immune system satisfies Cowan's criteria of complexity, but nobody is paying for that connection to be explored. The lessons, for students of academic entrepreneurship, is to go now and then in ten years, so see how it has come out. It will be tragic if the desert has taken over.

John Maddox 